\title{
THE IMPLEMENTATION OF A QUALITY MANAGEMENT SYSTEM: A CASE STUDY OF SERBIAN TRANSPORT ORGANIZATIONS
}

\author{
Sanja Žeželj ${ }^{1}$ \\ ${ }^{1}$ University of Belgrade, Faculty of Transport and Traffic Engineering, Vojvode Stepe 305, 11000 \\ Belgrade, Serbia
}

Received 10 June 2013; accepted 28 August 2013

\begin{abstract}
The aim of the following study is to analyze the quality of operations in local transport companies, which includes operations according to certain international, European and national standards and regulations. Special emphasis is placed on the research in the field of standards, quality system and the implementation of the ISO series of standards 9000 for road companies. The implementation of a Quality Management System (QMS) is essential for companies seeking competition on the international market. This paper presents the results of the research which was carried out in Serbia at the end of 2012 on the sample of enterprises by interviewing managers on quality culture as well as departments dealing with the quality system of the company. Interviewees are from the following companies: those that have introduced the ISO standards or other quality management system, companies that conduct consultations to introduce the system, etc. Although respondents ranked the quality management function as the second most important of them all, after the function of telecommunications companies, the research revealed that managers within transport companies in Serbia are insufficiently aware of the importance of introducing QMS for achieving better business operations. The research results within other services of surveyed companies show that this constitutes an unnecessary expense (for each company), and that the position of managers within these services is redundant. Thereinafter, the companies were ranked by their activities in the field of transportation, the number of employees and the type of organization.
\end{abstract}

Keywords: Quality Management System (QMS), transportation, traffic, implementation, ISO 9000, quality.

\section{Introduction}

Quality management is a systematic way of guaranteeing that the activities will be organized according to the plan drew up beforehand. It is a discipline that deals with management control, ensuring prevention. Quality management is an effective tool for solving all quality requirements and establishing a modern and innovative company. It is a set of actions and activities that affect the quality of products, work and organization (Fey and Gogue, 1994).

The introduction of a quality management system in a company leads to: a continuous and constant improvement, increased competitiveness, increased efficiency and profitability, clear procedures, reduction of errors, reduction of production time, better motivation, better communication and disclosure of information, improvement of

\footnotetext{
${ }^{1}$ Corresponding author: sanjazezelj86@gmail.com
} 
the image, safety and reliability of products and services, better management of human resources, and most importantly, focus on customers. The varieties of methods are used for the efficiency evaluation of decision making units (e.g. public transport companies). It is very often used in the transport sector for the efficiency assessment of airports, ports, railways and public transport companies (Markovits-Somogyi, 2011).

A service user is the one who determines quality, not the manufacturer. Quality evaluation is necessary to know the needs of the user. The focus on the buyer indicates that the concept of quality is based on marketing. The significant research has done in this field by Terziovski et al. (1997) within the study which was developed in order to test the strength of the relationship between ISO 9000 certification and organizational performance in the presence and absence of a total quality management (TQM) environment. The analysis was done a large random sample of manufacturing companies in Australia and New Zealand. Furthermore, the study reported by Salomone (2008) has been developed using a sample of Italian companies to investigate the potential for integration starting from an analysis of the common aspects in terms of real motivations (company image, costs saving, etc.), obstacles (unclear regulations, lack of financial support, etc.), driving forces and external pressures that companies meet when implementing each of the management systems analyzed: Quality (ISO 9001:2000), Environmental (ISO 14001:2004), Occupational Health and Safety (OHSAS 18001:1999), and even, Social Responsibility (SA 8000:2007) management systems. Based on a comprehensive literature review, some studies (Kaynak, 2003) identify the relationships among total quality management - TQM practices and examines the direct and indirect effects of these practices on various performance levels whilst other studies put forward a procedure for measuring the competencies that can be developed in association with a Quality Management ( $Q M)$ initiative and analyzes the reliability and validity of the resulting scale (Escrig-Tena and Bou-Llusar, 2005).

In recent years, numerous approaches have been proposed to improve operations performance (Kannan and Tan, 2005; Lin et al., 2005; Tsai and Chou, 2009; Calingo, 1996; Lai and Cheng, 2003; Yusuf, Y., Gunasekaran and Abthorpe, 2004; Van der Wiele et al., 1996; Trienekens and Zuurbier, 2008; Hull, 2008; Salomone, 2008). Three in particular, just in time, supply chain management, and quality management, have received considerable attention and this paper is based on the last mentioned strategy.

\section{The Importance of a Quality System}

Quality management system is a wide area where many terms are used depending on the user experience and the environment which could be explained in many different ways. This is the reason why basic terms used in the quality system managament are standardized and have a unique meaning.

ISO 9000 series of standards consists of standards and manuals which refer to the control system, terminology standards and resources which provide an overall explanation of that system.

The research presented in this paper was focused on the acquisition of quality culture by managers in Serbian transportation companies. The latest research shows that Serbian companies have not implemented the necessary reforms. However, there is the 
will to set up a proper system according to the requirements of certain organizations (Table 1).

One of the goals of this study was to determine the relationship between those responsible for the introduction of quality in companies and their attitude towards the introduction and implementation, as well as to compare the results we obtained with those of the companies in the EU.

Some organizations only want to acquire a formal certificate, but forget that their documents have to meet the standards, which according to Montgomery (2012) is their "Achilles heel". Such organizations represent themselves falsely because the ISO 9000 certificate merely guarantees that there is a quality system which enables the production process of a product and/or goods and the provision of services in the way it is guaranteed to the customer or user.

\section{Table 1}

The Number of Certificates Issued According to the ISO Standards in Serbia

\begin{tabular}{cc}
\hline Year & Number of certificates \\
\hline 2002 & 65 \\
2004 & 89 \\
2006 & 142 \\
2008 & 175 \\
2010 & 187 \\
2012 & 213 \\
\hline Total & $\mathbf{8 7 1}$ \\
\hline
\end{tabular}

Source: SORS (2012)

The results of the survey showed that the highest number of certified organizations can be found among transportation companies which compete to acquire the best possible position in the international market as well as telecommunications, sea and inland waterway transport, road transport, and air transport companies.

International competition and the search for regular customers forces the company to accept the quality system as its business philosophy and strategy. Considering that Serbia is on its way to become a member state of the European Union, a dramatic increase in the number of certificates in the next few years is foreseen. The results of the studies conducted in Serbia show that there is a correlation between business success and the quality system.

\section{Research Methodology}

The research was based on a survey of a representative sample of companies. Companies from all fields of transportation, of different sizes (Table 2) and from different parts of Serbia were equally represented in the survey (Table 3 ).

Data were collected using computerized telephone interview CATI ${ }^{2}$. General managers, directors of other sectors (if such a position exists), and members of the board were interviewed. The criteria used in selecting and grouping were: the size of the company and the transport sector of the company. This survey was undertaken in 2012. It focused on five issues: the importance of implementing QMS, informing employees about it, skilled personnel to perform quality, the attitude of employees to service QMS, the assessment of the success of implementation.

The survey contained over 550 companies, which were specialized in

\footnotetext{
${ }^{2}$ CATI (Computer-Assisted Telephone Interviewing) includes automatic data entry, as well as complete control of data entered. The market research agency Plus Ltd. collected the data using the software WEBCAT while the statistical software package SPSS was used for data processing.
} 
different activities in the field of traffic, such as planning offices, transportation companies - passengers and freight, freight forwarding, road construction companies, airlines, companies providing telecommunications services, and companies providing logistical support. The unit of analysis within this study was a company and the unit tested was a CEO or a manager of the company.

\section{Table 2}

The Structure of Surveyed Enterprises by Size

\begin{tabular}{lc}
\hline Number of employees & Structure \% \\
\hline More than 250 (large enterprise) & 25 \\
$51-250$ (medium-large enterprise) & 38 \\
15-50 (small enterprise) & 37 \\
\hline Total & $\mathbf{1 0 0 \%}$ \\
\hline
\end{tabular}

Source: SORS (2012)

Table 3

The Structure of Enterprises Surveyed by Region

\begin{tabular}{|c|c|c|}
\hline & & Structure \% \\
\hline \multirow{7}{*}{$\begin{array}{l}\stackrel{0}{0} \\
\widetilde{0}\end{array}$} & Belgrade & 34 \\
\hline & Vojvodina & 16 \\
\hline & Eastern Serbia & 14 \\
\hline & Western Serbia & 4 \\
\hline & Sumadija & 10 \\
\hline & Southern Serbia & 5 \\
\hline & Central Serbia & 17 \\
\hline \multicolumn{2}{|c|}{ Total } & $100 \%$ \\
\hline
\end{tabular}

Source: SORS (2012)

\section{The Results of the Research}

\subsection{The Acceptance of a Quality System}

Out of 550 companies which were surveyed, 105 of them, that is $19 \%$, have introduced a quality system, ISO or another one, while $14 \%$ received consulting for quality system implementation at the moment of benchmarking. Table 6 shows the total number of certified companies which were surveyed, the majority of them, over $51 \%$ are companies engaged in international transport, and much less, $11 \%$ are companies involved in designing of roads, the so-called road construction companies, telecommunications companies $19 \%$, transport enterprises which provide services only within Serbia 5\%, and other transportation companies account for $23 \%$.

Out of 183 selected companies whose business is mainly international transport (Table 4), over $29 \%$ had a certificate for some of the ISO standards, while $14 \%$ received consultations during the survey by a consulting agency. Transport activity was represented by 37 companies, of which less than $24 \%$ were certified, while $11 \%$ were following the procedure of preparation. Regarding other transport activities of those companies that were benchmarked, and whose operations were not specifically defined, but described as others, the sample was very small, less than 30 , and the population was unknown, so the conclusion we deduced on them was not taken into account because it did not provide reliable data.

At the beginning of the inquiry, when each respondent was asked detailed questions about possible preparations for the implementation of the quality system so that senior management (directors) could reach a decision, a significant degree of preparation and consultation for the implementation of ISO standards was found in freight industry and other businesses that operate on the international market. Out of 550 companies, $54 \%$ had a positive view regarding the introduction of QMS, i.e. ISO standards in their business and the introduction of certificates, as $22 \%$ were currently in the process of preparations and $32 \%$ received consultations, while the rest of 
the companies benchmarked were in some kind of boycott because they thought it was an unnecessary expense for them, not being part of international trends.

What is also evident in this sample is that out of 105 companies that have been certified as many as $65 \%$ are transport companies. The largest number of companies, as many as $49 \%$ of them, belongs to the same group with an active attitude towards quality system according to ISO 9000 . Only $14 \%$ had a poor attitude towards the introduction of certificates and these were mainly companies involved in some sort of traffic trade, the sales of finished products to road construction companies and alike (Table 5 and Table 6).

\section{Table 4}

The Structure of Enterprises Surveyed According to the Activities and the Implementation of the International Standard ISO

\begin{tabular}{lcc}
\hline Main occupation & Number of companies & Structure \% \\
\hline Domestic transport of people & 100 & 18 \\
International transport of people & 144 & 26 \\
Road industry & 63 & 12 \\
Shipping & 98 & 18 \\
Logistics & 30 & 5 \\
Telecommunications & 43 & 7 \\
Road safety agencies & 7 & 1 \\
Design offices & 3 & 1 \\
Air transport & 9 & 2 \\
Rail transport of passengers and goods & 53 & 10 \\
\hline Total & $\mathbf{5 5 0}$ & $\mathbf{1 0 0} \%$ \\
\hline
\end{tabular}

Source: SORS (2012)

Table 5

The Number of Enterprises by the Types of Activities and the Implementation of the International Standard ISO

\begin{tabular}{lccc}
\hline & Have certification \% & Preparing for certification \% & Other \% \\
Number of respondents & $\mathbf{1 0 5}$ & $\mathbf{7 5}$ & $\mathbf{3 7 0}$ \\
\hline International transport of goods & 51 & 30 & 29 \\
International transport of people & 11 & 13 & 27 \\
Container transport & 10 & 20 & 15 \\
Road Safety & 1 & 5 & 13 \\
Telecommunications & 14 & 11 & 6 \\
Road Industry- performers & 7 & 5 & 5 \\
Road Industry- design & 3 & 3 & 2 \\
Air Traffic & 1 & 5 & 1 \\
Logistics & 1 & 3 & 1 \\
Rail traffic and transport & 1 & 5 & 1 \\
\hline Total & $\mathbf{1 0 0}$ & $\mathbf{1 0 0 \%}$ & $\mathbf{1 0 0 \%}$ \\
\hline
\end{tabular}

Source: SORS (2012) 


\section{Table 6}

The Structure of Enterprises Surveyed by Group Activities and the Implementation of the International Standard ISO

\begin{tabular}{lccc}
\hline & Have certification \% & Preparing for certification \% & Other \% \\
Number of respondents & $\mathbf{1 0 5}$ & $\mathbf{7 5}$ & $\mathbf{3 7 0}$ \\
\hline Transport & 65 & 49 & 49 \\
Air transport & 14 & 20 & 22 \\
Telecommunications & 18 & 26 & 18 \\
Road industry & 3 & 5 & 11 \\
\hline Total & $\mathbf{1 0 0} \%$ & $\mathbf{1 0 0} \%$ & $\mathbf{1 0 0 \%}$ \\
\hline
\end{tabular}

Source: SORS (2012)

\subsection{The Implementation of a Quality System and Company Size}

The results of the inquiry are presented in Table 7 and Table 8. It can be concluded that the size of companies and the implementation of quality systems are statistically dependent values.

The greatest number of certificates was awarded to medium-sized companies, as much as $41 \%$, then to large companies, about $33 \%$, and finally to firms with 15 to 50 employees, $26 \%$.

Out of 210 medium-sized enterprises $20 \%$ of them had certificates, and $12 \%$ were in the process of implementing the quality system. Out of 135 large firms, $26 \%$ of them had certificates and $18 \%$ of them were in the process of receiving advice. Out of 205 small businesses in the sample, $13 \%$ had a certificate and $14 \%$ of them were preparing for it after the consultations with certification bodies.

\section{Table 7}

The Number of Surveyed Companies by Size and the Implementation of ISO

\begin{tabular}{lccc}
\hline Size of enterprises & Have certification & Preparing for certification & Other \\
\hline 15-50 (small enterprise) & 27 & 28 & 148 \\
$51-250$ (medium-sized enterprise) & 43 & 25 & 143 \\
More than 250 (large enterprise) & 35 & 22 & 79 \\
\hline Total & $\mathbf{1 0 5}$ & $\mathbf{7 5}$ & $\mathbf{3 7 0}$ \\
\hline
\end{tabular}

Source: SORS (2012) 
Table 8

The Structure of Surveyed Companies by Size and the Implementation of the ISO Standard

\begin{tabular}{lccc}
\hline Size of enterprises & Have certification \% & Preparing for certification \% & Other \% \\
Number of respondents & $\mathbf{1 0 5}$ & $\mathbf{7 5}$ & $\mathbf{3 7 0}$ \\
\hline $15-50$ (small enterprise) & 26 & 38 & 40 \\
$51-250$ (medium-sized enterprise) & 41 & 33 & 39 \\
More than 250 (large enterprise) & 33 & 29 & 21 \\
\hline Total & $\mathbf{1 0 0 \%}$ & $\mathbf{1 0 0 \%}$ & $\mathbf{1 0 0 \%}$ \\
\hline
\end{tabular}

Source: SORS (2012)

\subsection{The Reception of Quality Culture and the Types of Organization among Benchmarked Companies}

According to many authors that deal with the acquisition of quality, standardization will be one of the deciding factors on which Serbia's integration into the European Union will depend. To that effect, this research which was carried out among transportation organizations aims to determine companies' willingness to impose standardization. Table 9 and Table 10 show how many companies depending on their type of organization have introduced or plan to introduce a quality system or receive consultations regarding the introduction of a quality system.

Based on the sample and the results presented in these tables, $49 \%$ of certified companies are limited liability companies, while $50 \%$ are holding companies. Among those receiving consultations over organization type, Ltd. companies are more numerous, accounting for as much as $58 \%$, while holding companies account for only $41 \%$ with respect to the total number of companies.

\section{Table 9}

The Number of Enterprises by the Type of Organization and the Implementation of the International Standard

\begin{tabular}{lccc}
\hline Type of organization & Have certification & Preparing for certification & Other \\
\hline Ltd. & 51 & 43 & 226 \\
Holding companies & 53 & 31 & 128 \\
Other & 1 & 1 & 16 \\
\hline Total & $\mathbf{1 0 5}$ & $\mathbf{7 5}$ & $\mathbf{3 7 0}$ \\
\hline
\end{tabular}

Source: SORS (2012) 


\section{Table 10}

The Structure of Enterprises by the Type of Organization and the Implementation of the International Standard ISO

\begin{tabular}{lccc}
\hline Type of organization & Have certification \% & Preparing for certification \% & Other \% \\
Number of respondents & $\mathbf{1 0 5}$ & $\mathbf{7 5}$ & $\mathbf{3 7 0}$ \\
\hline Ltd. & 49 & 58 & 61 \\
Holding company & 50 & 41 & 35 \\
Other & 1 & 1 & 4 \\
\hline Total & $\mathbf{1 0 0} \%$ & $\mathbf{1 0 0 \%}$ & $\mathbf{1 0 0 \%}$ \\
\hline
\end{tabular}

Source: SORS (2012)

\subsection{The Importance of the Function Performed by Managers in the Company}

We asked the managers to give us their opinion of and assess the importance of selected business functions in our economy.
In companies with a certified quality system, the telecommunications function received the highest grade point average of 3.3 (on a scale of 1 to 4 ), while the quality management was in the second place, which can be seen in Table 11 .

\section{Table 11}

Average Scores of the Importance of Certain Functions in Companies with Different Levels of the Implementation of the International Standard ISO (from 1-Least Important, 4-Most Significant)

\begin{tabular}{lccc}
\hline & Have certification & Preparing for certification & Other \\
Number of respondents & $\mathbf{1 0 5}$ & $\mathbf{7 5}$ & $\mathbf{3 7 0}$ \\
\hline 1.Telecommunications & 3.30 & 3.17 & 3.34 \\
2. Quality Management & 3.07 & 0.97 & 3.10 \\
3. Marketing & 3.00 & 2.96 & 3.02 \\
4. Management & 2.96 & 2.96 & 2.92 \\
5. Human Resources & 2.95 & 2.73 & 2.92 \\
6. Finances & 2.87 & 2.64 & 2.84 \\
7. Production and Operational Processes & 2.87 & 2.69 & 2.90 \\
8. Public Relations & 2.71 & 2.69 & 2.77 \\
\hline
\end{tabular}

Source: SORS (2012)

The same results were obtained when we were looking at the entire sample, when the results of the companies were included, that is, the managers of companies that have and those that do not have a certificate for a Quality System.

\section{Conclusion}

This survey which was conducted on a representative sample of 550 transportation companies doing their business in different areas of transport and based on interviews with managers, boards and directors of those companies helped us determine the degree of the adoption of quality management systems.

Barring the fact that the majority of companies in Serbia have not introduced any of the above systems of quality according to the ISO 9000 (9001) standard, or any other, and judging by the results obtained, it can 
be noted that the interest in the necessity of implementing the system of quality in transportation companies has not yet been "awakened" nor is there sufficiently developed culture in this respect.

Results obtained in this study reject the opinion of the majority of managers that there is the greatest demand for trained personnel who could implement quality systems in companies of all types. The largest number of interviewed executives feel that the expertise of the managers who are working on the quality system and quality management is extremely poor, actually the poorest compared to other sectors.

In the opinion of all interviewees, the best managers are those who are in the field of telecommunications, marketing and then other jobs, and at the very end are managers from other fields of transport.

Considering only interviewees from companies that are certified, ratings are similar, insignificant difference can be noted, therefore these ratings were not reprocessed. The contradiction lies in the result which shows that the respondents considered that in Serbia managers of other activities are more sought after than those dealing with the quality system. This led us to more data which revealed that managers involved in the implementation of quality systems are the most numerous and the most sought after in companies dealing with: human resources management, finance, marketing, organization and management, etc.

It was surprising that only $12 \%$ of the interviewed directors, managers, and members of senior management of certified firms in the field of transport where the implementation of QMS is very important acknowledged to have a position in the business due to the introduced ISO standards and their work on the application of the standard, while the rest thought the standards were imposed regardless of the future quality of business operations of the company.

The survey results show that transport companies have a very small number of managers who deal with the quality system. Furthermore, companies show very little interest in obtaining or seeking consultations with respect to the introduction of QMS.

The worst situation is in companies that are located outside of Belgrade and in those which offer their services only to customers within Serbia. The fact that merely $11 \%$ out of 45 companies have a certificate of quality reveals a serious disagreement about the things which need to be improved in the future, and many will oppose the changes due to ignorance as well as major expenses necessary to implement QMS.

There are $81 \%$ of companies in the sample that did not introduce the quality system standard ISO (9000.9001), 17\% of companies of all respondents did not even bother to think about its introduction. However, the overall situation is still promising, because according to the survey, $37 \%$ of the companies studied are actively preparing for the introduction of quality systems.

In conclusion, the results indicate lack of awareness about the importance of systematic and continuous development of quality culture, as well as the training of quality managers and sustainable QMS functions in international trade and for overall prosperity. The results we obtained, 
given the spatial range of the research, can serve as a basis for research in other countries, especially in South-East Europe.

\section{References}

Calingo, L.M.R. 1996. The evolution of strategic quality management, International Journal of Quality \& Reliability Management. DOI: http://dx.doi. org/10.1108/02656719610150597, 13(9): 19-37.

Escrig-Tena, A.B.; Bou-Llusar, J.C. 2005. A Model for Evaluating Organizational Competencies: An Application in the Context of a Quality Management Initiative, Decision Sciences. DOI: http://dx.doi. org/10.1111/j.1540-5414.2005.00072.x, 36(2): 221-257.

Fey, R.; Gogue, J.M. 1994. La maitreise de la qualite, Economica. ISBN-10 2717820558, France.

Hull, A. 2008. Policy integration: what will it take to achieve more sustainable transport solutions in cities?, Transport Policy. DOI: http://dx.doi.org/10.1016/j. tranpol.2007.10.004, 15(2): 94-103.

Kannan, V.R.; Tan, K.C. 2005. Just in time, total quality management, and supply chain management: understanding their linkages and impact on business performance, Omega. DOI: http://dx.doi.org/10.1016/j. omega.2004.03.012, 33(2): 153-162.

Kaynak, H. 2003. The relationship between total quality management practices and their effects on firm performance, Journal of Operations Management. DOI: http://dx.doi.org/10.1016/S0272-6963(03)00004-4, 21(4): 405-435.

Lai, K.H.; Cheng, T.C.E. 2003. Initiatives and outcomes of quality management implementation across industries, Omega. DOI: http://dx.doi.org/10.1016/ S0305-0483(03)00021-5, 31(2): 141-154.
Lin, C.; Chow, W.S.; Madu, C.N.; Kuei, C.H.; Pei Yu, P. 2005. A structural equation model of supply chain quality management and organizational performance, International Journal of Production Economics. DOI: http:// dx.doi.org/10.1016/j.ijpe.2004.05.009, 96(3): 355-365.

Markovits-Somogy, R. 2011. Ranking Efficient and Inefficient Decision Making Units in Data Envelopment Analysis, International Journal for Traffic and Transport Engineering, 1(4): 245-256.

Montgomery, D.C. 2012. Intoduction to Statistical Quality Control, 6th Edition, Arizona State University, John Wiley \& Sons, Inc. 978-0-470-16992-6.

Salomone, R. 2008. Integrated management systems: experiences in Italian organizations, Journal of Cleaner Production. DOI: http://dx.doi.org/10.1016/j. jclepro.2007.12.003, 16(16): 1786-1806.

Statistical Office of the Republic of Serbia (SORS). 2012. Available from Internet: <http://webrzs.stat. gov.rs/WebSite/Default.aspx $>$.

Terziovski, M.; Samson, D.; Dow, D. 1997. The business value of quality management systems certification. Evidence from Australia and New Zealand, Journal of Operations Management. DOI: http://dx.doi.org/10.1016/ S0272-6963(96)00103-9, 15(1): 1-18.

Trienekens, J.; Zuurbier, P. 2008. Quality and safety standards in the food industry, developments and challenges, International Journal of Production Economics. DOI: http://dx.doi.org/10.1016/j.ijpe.2007.02.050, 113(1): 107-122.

Tsai, W.H.; Chou, W.C. 2009. Selecting management systems for sustainable development in SMEs: A novel hybrid model based on DEMATEL, ANP, and ZOGP, Expert Systems with Applications. DOI: http://dx.doi. org/10.1016/j.eswa.2007.11.058, 36(2): 1444-1458.

\section{ijtte 406}


Van derWiele, A.; Williams, A.R.T.; Dale, B.G.; Carter, G.; Kolb, F.; Luzon, D.M.; Schmidt, A.; Wallace, M. 1996. Self-assessment: a study of progress in Europe's leading organizations in quality management practices, International Journal of Quality \& Reliability Management. DOI: http://dx.doi.org/10.1016/10.1108/026567196 10108341, 13(1): 84-104.

Yusuf, Y.; Gunasekaran, A.; Abthorpe, M.S. 2004. Enterprise information systems project implementation: A case study of ERP in Rolls-Royce, International Journal of Production Economics. DOI: http://dx.doi. org/10.1016/j.ijpe.2003.10.004, 87(3), 251-266. 